\title{
REDUCTION OF NON-PERFORMING LOANS IN THE BANKING INDUSTRY: AN APPLICATION OF DATA ENVELOPMENT ANALYSIS
}

\author{
Chih-Ching YANG \\ Department of Marketing Management, Central Taiwan University of Science and Technology, \\ No. 666, Pu-tzu Road, Taichung 406, Taiwan, ROC \\ E-mail:107103@ctust.edu.tw
}

Received 13 December 2016; accepted 18 July 2017

\begin{abstract}
The increase in non-performing loans around the world has had quite a negative impact on many nations' banking systems. To address these problems, many creative regulatory solutions and well-designed risk techniques have been utilized in the hope of reducing non-performing loans to an acceptable level. The purpose of this study is to apply a newly developed data envelopment analysis model to suggest the most efficient plan (called Plan 4) to reduce non-performing loans that can maximize the efficiency of the entire banking industry's control over the bad debts. For comparison purpose, three other reduction plans are also represented. The four plans are presented using data from Taiwan's banking industry. The empirical results show that among the plans presented, Plan 4 shows the most effective allocation of the industry-wide reduction target. The plan focuses on a finite number of banks, helping identify the key units to improve industry-wide efficiency. The findings implicitly suggest that the regulator should devise more incentive measures to encourage target banks to perform the non-performing loan reduction task. Our results also suggest that for the regulator, forcing banks to cut their non-performing loans by the same ratio will not help improve the relative efficiency of the industry.
\end{abstract}

Keywords: banking industry, non-performing loan, risk management; data envelopment analysis, undesirable output, Taiwan.

JEL Classification: C44, C61, D24, G21.

\section{Introduction}

The global financial crisis has, since its onset in 2008, taken a toll on the world economy. Accompanying the crisis has been a severe contraction in economic activity. Financial institutions facing the crisis generally have exhibited unsafe and unsound practices. As a result, the quality of loan portfolios has deteriorated significantly, causing an increase in non-performing loans (NPLs) and sizeable profit reduction in banking systems. Because of their rising volume and their impact on the economy as a whole, on the banking system and on its credit supply, NPLs have been an increasingly hot topic in the international scene (Scardovi 2016). 
To control NPLs, the implementation of a well-designed risk management framework has been considered a must for a best-practice bank. To decide whether to approve a loan application, banks should evaluate the riskiness of the loan, decide an appropriate risk premium on the loan, devise measures to prevent as well as deal with possible loss events, and assess their ability to absorb losses when NPLs occur. Putting such a framework into practice would be expected to increase operational efficiency. If the risk management framework does not work, a plan for the reduction of NPLs is necessary.

Two interesting issues arise during the process. The first one is the role of NPLs in efficiency analysis and their impact on operational efficiency, which have drawn much attention from academic researchers. To investigate the problems, earlier studies generally used a two-stage approach. First, they estimated bank efficiency, and then used regression techniques, in which NPLs are an explanatory variable, to analyze the impact of the NPLs on efficiency. A general conclusion is that NPLs had a negative effect on efficiency (see e.g. Mester 1996; Berger, DeYoung 1997). The two-stage approach, however, does not include NPLs in efficiency estimation models. Assaf et al. (2013) argued that, in this way, the resulting efficiency scores are biased. The efficiency measure may overestimate a bank's performance if it produces a high percentage of NPLs, and underestimate those producing less. Fujii et al. (2014) also argued that neglecting NPLs will fail to credit a bank for its effort to deal with the undesirable outputs. A banking production process must be clearly defined based on both desirable and undesirable outputs.

The second issue is how to reduce NPLs. Research on this topic has generally studied the effect of creative regulatory solutions or management programs on the control over NPLs. For example, Erdinç and Gurov (2016) examine whether the implementation of advanced risk management techniques in compliance with the internal ratings-based approaches in the Basel Capital Accord reduced NPLs. Saha et al. (2016) propose a knowledge-driven automated compliance auditing scheme for the processing of loans to investigate whether loan applications are highly risky. Stijepović (2014) recommends a project called the Podgorica Approach for quantitative assessment of the recovery of NPLs which could return to performing status through a restructuring process. Other studies seek solutions to reduce NPLs by finding their determinants; see e.g. Vithessonthi (2016), Louzis et al. (2012), and Ghosh (2015).

The present article follows the strand of the first issue. The novelty is that we incorporate the second issue into bank efficiency analysis. When evaluating bank efficiency, "data envelopment analysis" (DEA) is considered a suitable and commonly used approach (Fethi, Pasiouras 2010; Luo 2003). This is especially true when NPLs are considered, because DEA can easily accommodate both multiple inputs and multiple outputs. In DEA literature, NPLs are termed undesirable outputs, being distinguished from standard outputs. From the viewpoint of efficiency evaluations, given a specific amount of inputs, the more standard outputs are produced, the more efficient a production unit is. Yet producing fewer undesirable outputs is better. Most existing bank efficiency works that considered NPLs just focused on the issue of efficiency and productivity analysis; see e.g. Zhu et al. (2015). To our knowledge, no studies have been conducted in the literature so far to address the problem of NPL reduction by using DEA. 
However, a few studies that use parametric approaches to explore the effect of NPLs on bank efficiency can also deal with the problem of NPL reduction in a different way. Pastor and Serrano (2005) measure a ratio between the minimum NPLs and observed NPLs, called risk management efficiency, with which one can evaluate by how much a bank should decrease NPLs to be efficient. Maggi and Guida (2011) estimate the cost function for Italian banks, and calculate the NPL impact on the operating cost. They represent the link between loans and NPLs by stressing the role of the geographical position of the bank, and gauge such geographical differences as extremely relevant to the possibility of controlling costs by reducing the level of loans and NPLs according to the performance of the different areas. Instead of using parametric approaches, the present paper applies non-parametric DEA approaches, which do not require any definitions to be made about a specific form of an underlying production function. Besides, the proposed approach can measure both the industry-level and bank-level performance of controlling NPLs, and disaggregate the industry-wide reduction target into the aim of each bank, which earlier studies using parametric approaches did not consider.

As such, the purpose of this study is to contribute to the literature by suggesting a newly developed DEA model for deriving a NPL reduction plan that improves industry efficiency most. We present and compare four NPL reduction plans, including (1) reduction according to a given rate of decrease, (2) reduction according to the efficiency with which a bank controls NPLs, (3) reduction according to a mixed strategy combining the first two, and (4) reduction suggested from the proposed DEA model to maximize the industry-wide efficiency of controlling NPLs. We use a dataset collected from Taiwan's banking industry to conduct an empirical study. The main finding is that Plan 4 can help identify a finite number of key banks to improve system efficiency most.

The remainder of this paper unfolds as follows. The next section discusses the existing DEA-based approaches for the reduction of undesirable outputs. Section 2 introduces the methodological issues and explains the details of the suggested reduction plans. Section 3 presents the data. In Sections 4 and 5, the empirical findings are presented and discussed.

\section{DEA models for controlling undesirable outputs: a brief review}

Our proposed models are based on a DEA-like approach. Before introducing the proposed models, it is necessary to explain where the suggested approach is grounded in the literature. As mentioned earlier, although there have been a large number of DEA publications involving empirical research on the banking industry, most of them have been published in the field of efficiency and productivity analysis. None have conducted studies on the reduction of NPLs. However, a few DEA studies have addressed the issue of allocating a reduction target of pollutants or greenhouse gas emissions among decision-making units (DMUs), which are also termed undesirable outputs.

Wu et al. (2013) introduce a bargaining game into a centralized DEA model so that DMUs compete with each other for the least reduction of emission permits. In doing so, the central authority can improve the overall efficiency by reallocating the remain- 
ing emission permits. The proposed approach is applied to a dataset of agricultural greenhouse gas emissions from 15 European Union members. Sun et al. (2014) discuss two mechanisms for the reduction of emission permits among a group of manufacturing companies. The first one supposes that one of the member firms dominates the allocation on behalf of the group, and the second one assumes that a central authority is responsible for coordinating the allocation among all group members. The result shows that the second mechanism, which can not only maximize the whole efficiency of the group but also improve efficiencies of individual firms, is a better choice than the first one.

Feng et al. (2015), however, argue that a centralized allocation plan suffers from an implementation difficulty in persuading DMUs to reach agreement. They propose a two-step method to mitigate this side effect. In the first step, they provide improved DEA-based centralized allocation models, and in the second step, two compensation schemes are developed for centralized allocation for carbon emission abatement across countries in the Organization for Economic Co-operation and Development. Wu et al. (2016b) incorporate DEA and its closest target technique into a carbon emission abatement allocation problem. First, they propose a two-stage optimal total abatement target identification approach, which is used to obtain the optimal total abatement level for the DMUs. Then, another two-stage approach is developed for allocating the optimal total abatement among the DMUs. Wu et al. (2016a) suggest a context-dependent DEA technique, which maximizes output revenue after the total reduced carbon dioxide emissions and energy intensity, to allocate national carbon dioxide emissions and energy intensity reduction targets over Chinese provincial industrial sectors.

Another series of studies employ zero sum gains DEA models to "reallocate" emission permits or pollutant emissions. Note that a zero-sum game or a reallocation plan means that the total undesirable outputs remain unchanged, rather than reduced, after allocation. However, we believe that after appropriate revision the models can also be applied to allocate reduction targets over DMUs. Gomes and Lins (2008) are the first applying the models. They evaluate a carbon dioxide emission reallocation scheme between non-Annex I and Annex I parties, which can be considered part of the Kyoto Protocol statement. For more related studies, see Pang et al. (2015) and Chiu et al. (2015).

The above brief review shows that, as we have noted earlier, no DEA studies have addressed the problem of NPL reduction. Previous studies just focused on one type of undesirable outputs-pollutants. And the proposed DEA-like approaches could be classified into two categories: centralized DEA and zero sum gains DEA. The suggested approaches either emphasize that a central agency vigorously intervenes in the allocation of reduction or introduce negotiation mechanisms for the allocation of reduction. Both the proposed models are mainly applied to deal with emission abatements between countries. Neither of them has developed schemes from the viewpoint of maximizing industry efficiency. In the banking industry, it is important to control NPLs from the viewpoint of the industry. As argued by Scardovi (2016), banks may not possess the skills necessary to develop a strategy that takes into account an industry-wide perspective. In the present article, we have considered this perspective by introducing new approaches. 


\section{Methodological issues and plans for the reduction of undesirable outputs}

\subsection{Measuring the efficiency of controlling undesirable outputs}

The proposed approaches aim at developing the best plan for the reduction of NPLs. Before introducing the suggested models, it is necessary to clarify how the best plan is defined. Since the central topic is to deal with NPLs, naturally the measurement of how efficiently NPLs are controlled would be an ideal index, and a plan that can maximize the index would be the best.

Assume that the banking industry evaluated is composed of $n=1, \ldots, N$ banks or DMUs. Each consumes inputs $x_{1}, \ldots, x_{I}$ to produce outputs $y_{1}, \ldots, y_{J}$, and in the process NPLs occur, which are considered undesirable outputs. To generalize the proposed models, assume that there are $b_{1}, \ldots, b_{K}$ undesirable outputs. Let $x_{i n}, y_{j n}$ and $b_{k n}$ respectively denote the $i$ th input, the $j$ th output and the $k$ th undesirable output of DMU $n$.

We use the concept of "sub-vector efficiency" (Frija et al. 2009; Pang et al. 2015), which is introduced to account for undesirable output dimensions only, to measure the efficiency of controlling undesirable outputs, i.e. the efficiency of controlling NPLs (E-NPL) in our case. The efficiency measure is basically similar to traditional radial measures. The general specification for evaluating E-NPL of DMU $o \in\{1, \ldots, \mathrm{N}\}$ is as follows:

$$
\begin{array}{ll}
\text { Min } & \theta \\
\text { s.t. } & \sum_{n=1}^{N} \lambda_{n} x_{i n} \leq x_{i o}, i=1, \ldots, I ; \\
& \sum_{n=1}^{N} \lambda_{n} y_{j n} \geq y_{j o}, j=1, \ldots, J ; \\
& \sum_{n=1}^{N} \lambda_{n} b_{k n} \leq \theta b_{k o}, k=1, \ldots, K ; \\
& \sum_{n=1}^{N} \lambda_{n}=1 ; \\
& \lambda_{n} \geq 0, n=1, \ldots, N ; \\
& \theta \text { is unconstrained in sign, }
\end{array}
$$

where $\theta$ is a shrinkage factor with a boundary between one and zero for the undesirable outputs, namely the measure of E-NPL in our case. $\theta<1$ shows a technically inefficient DMU because there exist undesirable output shrinkages. $\theta=1$ shows a technically efficient DMU because of no undesirable output shrinkages. A more illuminating exposition of the measure can be found when Model (1) is rewritten as a dual form, which we will explain later. $\lambda$ are non-negative weights that define the target operation unit as a linear combination of the sample observations. (1.5) is a convexity constraint, which allows the production technology to display variable returns to scale. Without this constraint, the production technology is assumed to exhibit constant returns to scale, which indicates that DMUs are operating at their optimal scale. Because there is no evidence 
to show that the banks under evaluation in this study are at their optimal scale, the underlying technologies are assumed to be variable returns to scale.

Another way that Model (1) is different from traditional models is that it includes undesirable outputs. In DEA literature, however, there has been so far no general agreement on modeling undesirable outputs in a model; for a discussion on this matter see, e.g., Liu et al. (2010). Before a general conclusion is reached, we consider all existing approaches to be valid. When measuring E-NPL, if outputs are given, a DMU producing fewer undesirable outputs is considered more efficient, and so is using fewer inputs. Therefore, many studies (e.g. Zhang 2008) treat undesirable outputs as inputs. Both inputs and undesirable outputs are something that is given, needed, or lost in order to get a particular desirable output. For a bank, issuing riskier loans and using more inputs should produce more revenue and gains, yet riskier loans are frequently accompanied by NPLs. Thus, in a service process of commercial banks, NPLs are treated as inputs (Pasiouras 2008).

Model (1) is used to measure E-NPL at the DMU level. What about the E-NPL at the "industry" level? To address this question, we modify the approach suggested by Ray and $\mathrm{Hu}(1997)$ to develop the desired model. Since the banking industry is made up of individual banks, let the industry's inputs, outputs and undesirable outputs be denoted by $X, Y$ and $B$. Then the observed data are

$$
\begin{aligned}
& X_{i}=\sum_{n=1}^{N} x_{i n}, i=1, \ldots, I ; \\
& Y_{j}=\sum_{n=1}^{N} y_{j n}, j=1, \ldots, J ; \\
& B_{k}=\sum_{n=1}^{N} b_{k n}, k=1, \ldots, K .
\end{aligned}
$$

A DEA model typically consists of two parts, the production possibility set and the evaluated point. As shown in Model (1), the observed data $\left(x_{i o}, y_{j o}, b_{k o}\right)$ are placed on the right-hand sides of the constraints (1.2)-(1.4), and the production frontier is formulated as the left-hand sides of the same constraints. The scale of an industry on average is $\mathrm{N}$ times as large as an individual bank, so the industry's production possibility set would be expanded outward $\mathrm{N}$ times more than those of (1.2)-(1.4). Let $\eta_{n}=N \lambda_{n}$, and replace $\left(x_{i o}, y_{j o}, b_{k o}\right)$ with $\left(X_{i}, Y_{j}, B_{k}\right)$. The model measuring industry-level E-NPL is as follows:

$$
\begin{aligned}
\text { Min } & \theta \\
\text { s.t. } & \sum_{n=1}^{N} \eta_{n} x_{i n} \leq X_{i}, i=1, \ldots, I ; \\
& \sum_{n=1}^{N} \eta_{n} y_{j n} \geq Y_{j}, j=1, \ldots, J ; \\
& \sum_{n=1}^{N} \eta_{n} b_{k n} \leq \theta B_{k}, k=1, \ldots, K ;
\end{aligned}
$$




$$
\begin{aligned}
& \sum_{n=1}^{N} \eta_{n}=N \\
& \eta_{n} \geq 0, n=1, \ldots, N, \\
& \theta \text { is unconstrained in sign. }
\end{aligned}
$$

We now turn to the issue of the reduction of undesirable outputs. Suppose that the industry wants to reduce undesirable outputs by $\alpha_{k} \beta_{k}$, where $\alpha_{k}$ is a reduction rate of the $k$ th undesirable output, $0<\alpha_{k}<1$. Then the next question is how much each DMU should reduce undesirable outputs. We suggest using the following formula to derive possible plans.

$$
d_{k n}=\beta_{k} b_{k n}+\left(\frac{1-\theta_{n}^{*}}{\sum_{o=1}^{N}\left(1-\theta_{o}^{*}\right)}\right)\left(\alpha_{k}-\beta_{k}\right) B_{k}, n=1, \ldots, N ; k=1, \ldots, K,
$$

where $d_{k n}$ denotes the reduction of the $k$ th undesirable output of DMU $n$, and $\theta^{*}$ is DMUs' E-NPL before reduction. Specifically, formula (6) divides $\alpha_{k}$ into two parts, $\beta_{k}$ and $\alpha_{k}-\beta_{k}$, where $\beta_{k}$ is a plan parameter, $\beta_{k} \leq \alpha_{k}$. Defining $\beta_{k}$ with different numerical values, various reduction plans are suggested. We further define a DMU's responsibility of reduction as consisting of two parts accordingly. The first part, $\beta_{k} b_{k n}$, delimits a given responsibility for each DMU according to its own NPLs. The more NPLs a DMU produces, the more reduction it should undertake. The second part, $\left(1-\theta_{n}^{*}\right)\left(\alpha_{k}-\beta_{k}\right) B_{k} / \sum_{o=1}^{N}\left(1-\theta_{o}^{*}\right)$, assigns a share of responsibility for each DMU according to the entire industry's NPLs and how inefficiently the DMU controls NPLs before reduction. The more inefficient a DMU is, the more reduction it should undertake.

\subsection{Plan 1}

Let $\beta_{k}=\alpha_{k}$. Then (6) becomes

$$
d_{k n}=\alpha_{k} b_{k n}, n=1, \ldots, N ; k=1, \ldots, K .
$$

The plan simply suggests that each DMU should reduce its undesirable outputs by $\alpha_{k} b_{k}$. Because for every DMU and the industry, the reduction rate is the same, this would be considered fair.

\subsection{Plan 2}

One may argue that, however, Plan 1 is not truly fair, because an efficient DMU and an inefficient DMU assume the same reduction responsibility. To consider efficiency discrepancies, let $\beta_{k}=0$; then (6) becomes

$$
d_{k n}=\left(\frac{1-\theta_{n}^{*}}{\sum_{o=1}^{N}\left(1-\theta_{o}^{*}\right)}\right) \alpha_{k} B_{k}, n=1, \ldots, N ; k=1, \ldots, K .
$$


This plan suggests that a "relatively" efficient DMU does not need to assume any reduction responsibility. And the more inefficient a DMU is, the more reduction it should undertake. From the viewpoint of individual efficiency, the plan seems fairer than Plan 1.

\subsection{Plan 3}

It should be noted that the efficiency scores derived from DEA models are based on the concept of relative efficiency, rather than absolute efficiency. For a relatively efficient DMU, it is still possible to reduce its undesirable outputs. This implies that Plan 2 would be impractical. As such, an alternative scheme is to combine Plans 1 and 2.

Let $0<\beta_{k}<\alpha_{k}$. Then giving $\beta_{k}$ an arbitrary value within the range, a third plan can be defined.

\subsection{Plan 4}

We suppose that Plans 1-3 could not be the best plan that we defined earlier. The best plan must be able to maximize industry-level E-NPL. In what follows we will extend Model (5) to develop the desired plan. First, Model (5) is rewritten as the following dual form:

$$
\begin{aligned}
\operatorname{Max} & \sum_{j=1}^{J} u_{j} Y_{j}-\sum_{i=1}^{I} v_{i} X_{i}-N \delta \\
\text { s.t. } & \sum_{k=1}^{K} s_{k} B_{k}=1 ; \\
& \sum_{j=1}^{J} u_{j} y_{j n}-\sum_{i=1}^{I} v_{i} x_{i n}-\sum_{k=1}^{K} s_{k} b_{k n}-\delta \leq 0, n=1, \ldots, N ; \\
& u_{j}, v_{i}, s_{k} \geq \varepsilon>0, \quad i=1, \ldots, I ; j=1, \ldots, J ; k=1, \ldots, K ;
\end{aligned}
$$

$\delta$ is unconstrained in sign,

where $u_{j}, v_{i}$, and $s_{k}$ are unknown weights attached to outputs, inputs, and undesirable outputs, respectively, $\varepsilon$ is a non-Archimedean constant, and $\delta$ is a variable that allows the underlying technology to be variable returns to scale. Model (9) can be further rearranged as follows:

$$
\begin{aligned}
& \operatorname{Max} \frac{\sum_{j=1}^{J} u_{j} Y_{j}-\sum_{i=1}^{I} v_{i} X_{i}-N \delta}{\sum_{k=1}^{K} s_{k} B_{k}} \\
& \text { s.t. } \frac{\sum_{j=1}^{J} u_{j} y_{j n}-\sum_{i=1}^{I} v_{i} x_{i n}-\delta}{\sum_{k=1}^{K} s_{k} b_{k n}} \leq 1, n=1, \ldots, N ; \\
& u_{j}, v_{i}, s_{k} \geq \varepsilon>0, i=1, \ldots, I ; j=1, \ldots, J ; k=1, \ldots, K ; \\
& \delta \text { is unconstrained in sign. }
\end{aligned}
$$

According to the duality property, the optimal values of the objective functions for Models (5), (9), and (10), i.e. the efficiency measure, are the same, but Model (10) provides a more illuminating exposition of the measure. The efficiency of controlling undesirable 
outputs can be defined as a maximum ratio of net production, weighted outputs minus weighted inputs, to weighted undesirable outputs.

Instead of using Eq. (6), we modify Model (9) to determine $d_{k n}$ because the solution of a linear programming problem is an optimal one picked from numerous feasible ones. From a theoretical point of view, Plans 1-3 could be some of the possible solutions of the following programming model, but only the plan derived from the model is optimal. However, Plans 1-3 may be applied in practice, and provide a contrast to the best plan so as to facilitate the understanding of its merits.

We modify Model (9) as follows to determine Plan 4:

$$
\begin{aligned}
\text { Max } & \sum_{j=1}^{J} u_{j} Y_{j}-\sum_{i=1}^{I} v_{i} X_{i}-N \delta \\
\text { s.t. } & \sum_{k=1}^{K} s_{k}\left(1-\alpha_{k}\right) B_{k}=1 ; \\
& \sum_{j=1}^{J} u_{j} y_{j n}-\sum_{i=1}^{I} v_{i} x_{i n}-\sum_{k=1}^{K} s_{k}\left(b_{k n}-d_{k n}\right)-\delta \leq 0, n=1, \ldots, N ; \\
& \sum_{n=1}^{N} d_{k n}=\alpha_{k} B_{k}, k=1, \ldots, K ; \\
& b_{k n}-d_{k n}>0, k=1, \ldots, K ; n=1, \ldots, N ; \\
& d_{k n} \leq\left(1-\theta_{n}^{*}+\alpha_{k}\right) b_{k n}, k=1, \ldots, K ; n=1, \ldots, N ; \\
& u_{j}, v_{i}, s_{k} \geq \varepsilon>0, i=1, \ldots, I ; j=1, \ldots, J ; k=1, \ldots, K \\
& d_{k n} \geq 0, k=1, \ldots, K ; n=1, \ldots, N ; \\
& \delta \text { is unconstrained in sign. }
\end{aligned}
$$

Note that in Model (11) DMUs' reductions $d_{k n}$ are unknown decision variables. Constraint (11.4) shows that the sum of DMUs' reductions is equal to the industry-wide reduction. (11.5) is added to avoid the situation that any DMU's reduction is larger than its original volume. Constraint (11.6), where $\theta_{n}^{*}$ are DMUs' E-NPL before reduction, is added to keep the features of formulas (6)-(8). The constraint sets a maximal value of reduction; the more inefficient before reduction a DMU is, the larger value it is given. The maximal reduction for an efficient DMU is $\alpha_{k} b_{k n}$.

Model (11) is non-linear. Let $t_{k n}=s_{k} d_{k n}$. It can be rewritten as the following linear form:

$$
\begin{aligned}
\operatorname{Max} & \sum_{j=1}^{J} u_{j} Y_{j}-\sum_{i=1}^{I} v_{i} X_{i}-N \delta \\
\text { s.t. } & \sum_{k=1}^{K} s_{k}\left(1-\alpha_{k}\right) B_{k}=1 ; \\
& \sum_{j=1}^{J} u_{j} y_{j n}-\sum_{i=1}^{I} v_{i} x_{i n}-\sum_{k=1}^{K}\left(s_{k} b_{k n}-t_{n k}\right)-\delta \leq 0, n=1, \ldots, N ;
\end{aligned}
$$




$$
\begin{aligned}
& \sum_{n=1}^{N} t_{k n}=s_{k} \alpha_{k} B_{k}, k=1, \ldots, K ; \\
& s_{k} b_{k n}-t_{k n}>0, k=1, \ldots, K, n=1, \ldots, N ; \\
& t_{k n} \leq\left(1-\theta_{n}^{*}+\alpha_{k}\right) s_{k} b_{k n}, k=1, \ldots, K ; n=1, \ldots, N ; \\
& u_{j}, v_{i}, s_{k} \geq \varepsilon>0, i=1, \ldots, I ; j=1, \ldots, J ; k=1, \ldots, K ; \\
& t_{k n} \geq 0, k=1, \ldots, K, n=1, \ldots, N, \\
& \delta \text { is unconstrained in sign. }
\end{aligned}
$$

Using Model (12), we can find optimal values of $t_{n k}^{*}$ and $s_{k}^{*}$. Let $d_{k n}=t_{k n}^{*} / s_{k}^{*}$. The best reduction plan maximizing industry-wide E-NPL can then be found.

\section{Data}

The four reduction plans have been computed using data for Taiwan's banking industry. Controlling NPLs has long been an issue in Taiwan. Since the early 1990s, Taiwan's authorities have relaxed regulations and restrictions in exchange for greater participation of private entities. In the banking industry, the liberalization stimulated the development of the financial markets but also encouraged aggressive banking practices. A large number of new banks often engaged in unsound business practices in order to expand their market share. As a result, Taiwan's banking system suffered from an increase in NPLs and a number of financially troubled banks (Yang 2014).

In conducting the proposed models, the first step is the determination of inputs and outputs in banking service. However, in DEA literature, the selection of the inputs and outputs is typically different (Paradi, Zhu 2013). To identify the inputs and outputs, two approaches are commonly used: the production approach and the intermediation approach. In the production approach, a bank is considered to be a firm using its staff, equipment, floor space, etc. to serve its clients, and eventually attracting different types of deposit and loan accounts. Under the intermediation approach, banks are thought of as a financial intermediary between savers and borrowers. One of the most significant differences between the two approaches is the classification of deposits. The production approach regards deposits as outputs, while the intermediation approach considers deposits to be inputs (Holod, Lewis 2011; Paradi, Zhu 2013). Because the goal of reducing NPLs is to address the problem between lenders and borrowers, the intermediation approach is adopted for our case.

The intermediation approach generally posits that deposits, along with labor and physical capital, are inputs, whereas loans and securities are outputs. Yet, granting loans and investing in securities are expected to generate revenue in the end. Therefore, the output used in this study includes revenue and gains $(y)$. The inputs include personnel expenses $\left(x_{1}\right)$, fixed assets $\left(x_{2}\right)$, and deposits $\left(x_{3}\right)$. NPLs are the by-product of the intermediation process, and are regarded as an undesirable output $(b)$. 
Taiwan's banking industry currently includes 37 banks. Although Taiwan's authorities have relaxed restrictions on the financial sector, the banking industry is regulated by the Financial Supervisory Commission, which is responsible for the development, supervision, regulation, and examination of financial markets and financial service enterprises. The proposed DEA models are suitable for the case study because they are developed from the viewpoint of the industry-wide development authority or the regulator. We have collected the input and output data from the public information system on the official website of the Financial Supervisory Commission. The data were annual information reported for the year 2015. Table 1 presents the descriptive statistics of the input and output variables.

Table 1. Descriptive statistics of inputs and outputs

\begin{tabular}{lcccccc}
\hline \multicolumn{1}{c}{ Inputs/outputs } & Mean & Std. dev. & Min & Max & Skewness & Kurtosis \\
\hline Personnel expenses $\left(x_{1}\right)$ & 5,799 & 4,760 & 389 & 19,814 & 1.024 & 0.506 \\
\hline Fixed assets $\left(x_{2}\right)$ & 13,347 & 18,073 & 555 & 96,728 & 3.089 & 12.245 \\
\hline Deposits $\left(x_{3}\right)$ & 933,367 & 886,416 & 62,550 & $3,838,479$ & 1.318 & 1.608 \\
\hline Revenue and gains $(y)$ & 55,673 & 63,965 & 1,444 & 308,051 & 2.185 & 5.955 \\
\hline NPLs $(b)$ & 1,602 & 1,626 & 37 & 6,805 & 1.652 & 2.499 \\
\hline
\end{tabular}

Notes: Inputs and outputs are in millions of NT dollars.

\section{Empirical results}

Models (1) and (5) have been used to compute bank-level E-NPL and industry-level ENPL respectively. The results are listed in column 3, Table 2. The computed E-NPL is much lower than we expected. Although 10 banks are relatively efficient in controlling NPLs, the industry-level E-NPL is only 0.301. This is because inefficient banks' E-NPL is extremely low; most of them have a score less than 0.4 (see Fig. 1, the distribution of E-NPL scores). Since the industry-level E-NPL is only 0.301 , it is indeed necessary to reduce NPLs in the industry, and the decrease should be massive. Otherwise, efficiency improvement would be insignificant. Figure 1 also shows that banks' E-NPL scores have a bimodal distribution, with some clustered to the efficient end, but with over half being highly inefficient. Intuitively, in this case, one may suggest that the NPL reduction should aim at low E-NPL banks. That is exactly what Plan 2 suggests.

To investigate the suggestion, we conduct a scenario analysis of reducing industry-wide NPLs by $20 \%$; namely the parameter $\alpha$ is given by 0.2 . All four reduction plans have been computed. Unfortunately, we find that Plan 2 is infeasible. In viewing Eq. (8), one can see that if a bank's E-NPL is extremely low and the reduction parameter is given with a larger figure, the bank's reduction volume would be considerable. For a bank with modest original NPLs, the reduction target would exceed its original outputs, and as a result this is infeasible. The original NPLs of the sample banks are listed in column 2, Table 2. Take, for instance, Bank 23. Its original NPLs are 175. According to Eq. (8), its reduction target is 306 , which is infeasible. 
Table 2. Scenario of reducing NPLs by $20 \%$

\begin{tabular}{|c|c|c|c|c|c|c|c|c|}
\hline \multirow[t]{2}{*}{ Bank } & \multicolumn{2}{|c|}{ Original } & \multicolumn{2}{|c|}{ Plan 1} & \multicolumn{2}{|c|}{ Plan $3^{*}$} & \multicolumn{2}{|c|}{ Plan 4} \\
\hline & NPLs & E-NPL & reduction & E-NPL & reduction & E-NPL & reduction & E-NPL \\
\hline 1 & 5603 & 1.000 & 1121 & 1.000 & 784 & 1.000 & 0 & 1.000 \\
\hline 2 & 3320 & 0.133 & 664 & 0.133 & 623 & 0.137 & 0 & 0.133 \\
\hline 3 & 6805 & 0.113 & 1361 & 0.113 & 1115 & 0.116 & 6040 & 1.000 \\
\hline 4 & 2761 & 0.378 & 552 & 0.378 & 500 & 0.397 & 0 & 0.364 \\
\hline 5 & 3070 & 0.201 & 614 & 0.201 & 576 & 0.212 & 0 & 0.201 \\
\hline 6 & 2843 & 0.189 & 569 & 0.189 & 547 & 0.198 & 0 & 0.189 \\
\hline 7 & 1548 & 0.228 & 310 & 0.229 & 358 & 0.244 & 0 & 0.228 \\
\hline 8 & 1795 & 1.000 & 359 & 1.000 & 251 & 1.000 & 0 & 1.000 \\
\hline 9 & 1599 & 1.000 & 320 & 1.000 & 224 & 1.000 & 0 & 1.000 \\
\hline 10 & 808 & 0.046 & 162 & 0.046 & 288 & 0.059 & 0 & 0.046 \\
\hline 11 & 1341 & 0.502 & 268 & 0.501 & 279 & 0.543 & 0 & 0.501 \\
\hline 12 & 1096 & 0.222 & 219 & 0.222 & 296 & 0.262 & 0 & 0.218 \\
\hline 13 & 175 & 1.000 & 35 & 1.000 & 25 & 1.000 & 35 & 1.000 \\
\hline 14 & 358 & 0.252 & 72 & 0.253 & 187 & 0.455 & 0 & 0.243 \\
\hline 15 & 4905 & 0.055 & 981 & 0.055 & 860 & 0.053 & 0 & 0.055 \\
\hline 16 & 1084 & 0.121 & 217 & 0.121 & 313 & 0.135 & 0 & 0.120 \\
\hline 17 & 1318 & 0.059 & 264 & 0.060 & 357 & 0.047 & 0 & 0.059 \\
\hline 18 & 37 & 1.000 & 7 & 1.000 & 5 & 1.000 & 0 & 1.000 \\
\hline 19 & 129 & 1.000 & 26 & 1.000 & 18 & 1.000 & 0 & 1.000 \\
\hline 20 & 64 & 1.000 & 13 & 1.000 & 9 & 1.000 & 13 & 1.000 \\
\hline 21 & 341 & 0.350 & 68 & 0.350 & 167 & 0.591 & 0 & 0.291 \\
\hline 22 & 935 & 0.402 & 187 & 0.402 & 240 & 0.449 & 0 & 0.402 \\
\hline 23 & 175 & 0.211 & 35 & 0.214 & 169 & 1.000 & 0 & 0.211 \\
\hline 24 & 957 & 0.039 & 191 & 0.039 & 310 & 0.045 & 0 & 0.039 \\
\hline 25 & 229 & 0.447 & 46 & 0.447 & 133 & 0.919 & 172 & 1.000 \\
\hline 26 & 152 & 0.569 & 30 & 0.570 & 100 & 1.000 & 32 & 0.718 \\
\hline 27 & 853 & 0.273 & 171 & 0.273 & 253 & 0.334 & 628 & 1.000 \\
\hline 28 & 884 & 1.000 & 177 & 1.000 & 124 & 1.000 & 177 & 1.000 \\
\hline 29 & 2143 & 0.339 & 429 & 0.338 & 421 & 0.362 & 1418 & 1.000 \\
\hline 30 & 1350 & 0.612 & 270 & 0.611 & 260 & 0.652 & 534 & 0.999 \\
\hline 31 & 753 & 1.000 & 151 & 1.000 & 105 & 1.000 & 0 & 1.000 \\
\hline 32 & 1655 & 0.075 & 331 & 0.075 & 401 & 0.085 & 0 & 0.066 \\
\hline 33 & 1138 & 0.657 & 228 & 0.657 & 222 & 0.702 & 0 & 0.656 \\
\hline 34 & 593 & 0.331 & 119 & 0.332 & 205 & 0.436 & 0 & 0.327 \\
\hline 35 & 290 & 0.198 & 58 & 0.200 & 187 & 0.467 & 232 & 1.000 \\
\hline 36 & 1791 & 1.000 & 358 & 1.000 & 251 & 1.000 & 0 & 1.000 \\
\hline 37 & 4372 & 0.577 & 874 & 0.577 & 689 & 0.589 & 2573 & 1.000 \\
\hline industry & 59270 & 0.301 & 11854 & 0.301 & 11854 & 0.317 & 11854 & 0.376 \\
\hline
\end{tabular}

Notes: * The computed results of Plan 3 are based on $\beta=0.14$. 


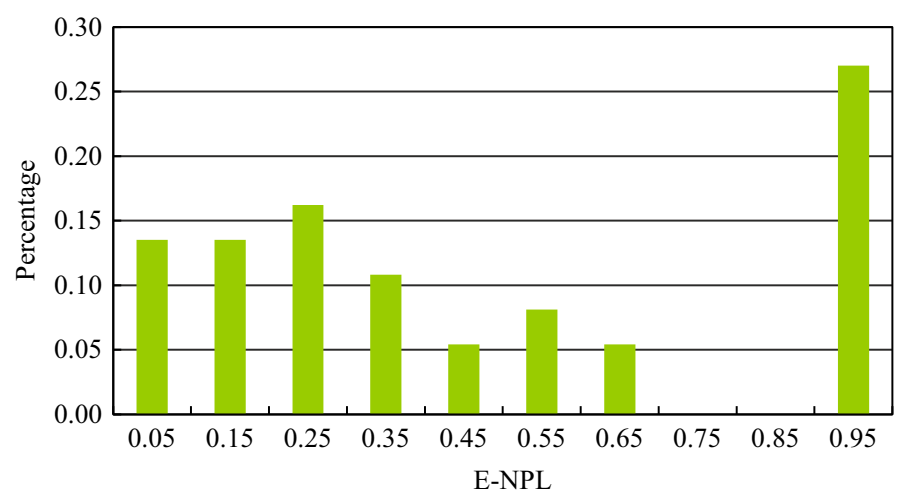

Fig. 1. Distribution of E-NPL

We turn to Plan 3, which partially preserves the feature of Plan 2. Because Plan 2 is defined by letting $\beta=0$, we assign $\beta$ a new figure as small as possible. However, the plans are also not feasible until $\beta=0.14$. The resulting reduction for each bank is listed in column 6 . Then computing each bank's NPLs after reduction and rerunning Models (1) and (5), we can find new bank-level and industry-level E-NPL when the plan is carried out. The results are listed in column 7 . The outcomes show that almost all inefficient banks' E-NPL is improved, with the exception of Banks 15 and 17; efficient banks remain efficient, and industry-level E-NPL is improved as well, from 0.301 to 0.317. However, the extent of improvement is smaller than expected. In a traditional DEA model using a radial input-oriented measure, if an inefficient DMU's inputs are reduced by $20 \%$, the efficiency score would be expected to increase 0.2 . The unexpected results can be explained by the structure of Model (1). In the model, when reduction is carried out, all bank's NPLs are changed. Thus both sides of the inequality (1.4) would be changed as well, possibly to the same direction. This would lead to less significant efficiency improvement. However, in a traditional model, reducing an inefficient DMU's undesirable outputs cannot change the left-hand side of the inequality, but will make the observed point closer to the frontier, leading to more significant efficiency improvement.

The phenomenon can be seen more clearly in Plan 1. Using this plan, each bank's reduction is listed in column 4. After reduction, bank-level and industry-level E-NPL are listed in column 5. One can see that banks' E-NPL is almost the same as that before reduction, and industry-level E-NPL stays at 0.301 . In other words, the plan cannot improve industry-wide efficiency at all. The results show the limitation of applying a DEA model, since its resulting efficiency is a "relative" concept. When all banks' NPLs are reduced by the same rate, highly efficient banks remain highly efficient, and vice versa. To improve relative efficiency, highly efficient banks should produce more NPLs, while inefficient banks should reduce NPLs. For efficient banks, this does not make sense. Or one may suggest that the reduction should focus only on inefficient banks. Yet, that is exactly the idea of Plan 2, which we have shown to be infeasible above. Therefore, we suggest another one, Plan 4. 
Model (12) is used to compute each bank's reduction. The results are listed in column 8. Again, we compute each bank's NPLs after reduction and then rerun Models (1). The resulting E-NPL is listed in column 9. As for industry-level E-NPL, Model (12) has calculated it, or one can rerun Model (5). The results are the same. Through this plan, industry-level E-NPL increases to 0.376, larger than the E-NPL derived from Plans 1 and 3. This is not surprising. As said earlier, the resulting industry-level E-NPL based on this plan is the largest when giving a reduction target. Only 11 banks are assigned the task of reduction. One may expect that these should be the least efficient banks. To our surprise, many extremely inefficient banks, e.g. Banks 10, 15, 17, 24, and 32, are not assigned this task. From a methodological perspective, Plan 4 tries to find a scheme maximizing the ratio of net production (weighted outputs minus weighted inputs) to NPLs at the industry level, which is possibly more sensitive to big banks. We find that those which are not assigned the task of reduction are mostly small banks. The focus is that once a bank is chosen to perform reduction, the reduction would eventually make them become efficient. Besides, an odd result is that a few efficient banks are also assigned the reduction task, but after reduction, they are still efficient. This may be because the production frontier must be adjusted, so the industry-wide efficiency can be maximized. Moreover, efficient banks' reduction is relatively modest compared to inefficient ones; see Banks 13, 20, and 28. One of the reasons is that we have added a constraint, i.e. the inequality (11.6), to make a reduction distinction between efficient and inefficient banks.

To confirm the above empirical findings, we conduct another scenario analysis of reducing the whole industry's NPLs by $40 \%$. The results are shown in Table 3. Using Plan 1 , again, both bank-level and industry-level E-NPL scores are almost the same as their original levels. As for Plan 2, due to a larger amount of reduction, it is only natural that the reduction is infeasible. To employ Plan 3, the parameter $\beta$ must be at least 0.36 . The results are listed in columns 6 and 7. Similar to the results of a $20 \%$ reduction, the plan can improve E-NPL more than Plan 1. However, the resulting E-NPL is very close to that of the scenario of reducing $20 \%$. Possible reasons are that because $\beta$ is given by 0.36 , very close to $\alpha=0.4$, its effect upon efficiency improvement is, as a result, similar to Plan 1 . Therefore, even though the amount of reduction is larger, the improvement effect is very close to that of the scenario of reducing $20 \%$. If conducting Plan 4, industry-level E-NPL increases to 0.501, again, larger than the results of Plans 1 and 3 . To carry out the plan, only 20 banks are needed. And after reduction, almost all these banks will become efficient.

As noted in the introduction section, many previous studies have explored the role of NPLs in efficiency analysis, and found that NPLs have a negative effect on efficiency (Mester 1996; Berger, DeYoung 1997). The argument suggests that the reduction of NPLs can improve a bank's efficiency. Our empirical results agree with this in general. But we have investigated more from a different point of view and obtained following two important cautions when applying the argument. First, past studies mostly explored how NPLs will impact bank efficiency from an individual point of view. The present article, on the other hand, explored how the reduction of NPLs will affect individual 
Table 3. Scenario of reducing NPLs by $40 \%$

\begin{tabular}{|c|c|c|c|c|c|c|c|c|}
\hline \multirow{2}{*}{ Bank } & \multicolumn{2}{|c|}{ Original } & \multicolumn{2}{|c|}{ Plan 1} & \multicolumn{2}{|c|}{ Plan $3^{*}$} & \multicolumn{2}{|c|}{ Plan 4} \\
\hline & NPLs & E-NPL & Reduction & E-NPL & Reduction & E-NPL & Reduction & E-NPL \\
\hline 1 & 5603 & 1.000 & 2241 & 1.000 & 2017 & 1.000 & 0 & 1.000 \\
\hline 2 & 3320 & 0.133 & 1328 & 0.133 & 1301 & 0.138 & 0 & 0.133 \\
\hline 3 & 6805 & 0.113 & 2722 & 0.113 & 2558 & 0.116 & 6040 & 1.000 \\
\hline 4 & 2761 & 0.378 & 1104 & 0.378 & 1070 & 0.395 & 0 & 0.364 \\
\hline 5 & 3070 & 0.201 & 1228 & 0.201 & 1203 & 0.211 & 2452 & 1.000 \\
\hline 6 & 2843 & 0.189 & 1137 & 0.189 & 1122 & 0.198 & 387 & 0.219 \\
\hline 7 & 1548 & 0.228 & 619 & 0.228 & 651 & 0.245 & 0 & 0.228 \\
\hline 8 & 1795 & 1.000 & 718 & 1.000 & 646 & 1.000 & 0 & 1.000 \\
\hline 9 & 1599 & 1.000 & 640 & 1.000 & 576 & 1.000 & 0 & 1.000 \\
\hline 10 & 808 & 0.046 & 323 & 0.045 & 407 & 0.059 & 0 & 0.022 \\
\hline 11 & 1341 & 0.502 & 536 & 0.502 & 544 & 0.539 & 668 & 0.999 \\
\hline 12 & 1096 & 0.222 & 438 & 0.221 & 490 & 0.257 & 857 & 0.999 \\
\hline 13 & 175 & 1.000 & 70 & 1.000 & 63 & 1.000 & 70 & 1.000 \\
\hline 14 & 358 & 0.252 & 143 & 0.251 & 220 & 0.420 & 0 & 0.235 \\
\hline 15 & 4905 & 0.055 & 1962 & 0.055 & 1881 & 0.054 & 4637 & 0.997 \\
\hline 16 & 1084 & 0.121 & 434 & 0.121 & 498 & 0.136 & 953 & 0.996 \\
\hline 17 & 1318 & 0.059 & 527 & 0.059 & 589 & 0.056 & 1240 & 0.997 \\
\hline 18 & 37 & 1.000 & 15 & 1.000 & 13 & 1.000 & 0 & 1.000 \\
\hline 19 & 129 & 1.000 & 52 & 1.000 & 46 & 1.000 & 31 & 1.000 \\
\hline 20 & 64 & 1.000 & 26 & 1.000 & 23 & 1.000 & 26 & 1.000 \\
\hline 21 & 341 & 0.350 & 136 & 0.348 & 202 & 0.550 & 0 & 0.219 \\
\hline 22 & 935 & 0.402 & 374 & 0.402 & 410 & 0.449 & 0 & 0.402 \\
\hline 23 & 175 & 0.211 & 70 & 0.210 & 159 & 1.000 & 146 & 1.000 \\
\hline 24 & 957 & 0.039 & 383 & 0.038 & 462 & 0.047 & 0 & 0.021 \\
\hline 25 & 229 & 0.447 & 92 & 0.447 & 150 & 0.831 & 218 & 1.000 \\
\hline 26 & 152 & 0.569 & 61 & 0.569 & 107 & 1.000 & 0 & 0.567 \\
\hline 27 & 853 & 0.273 & 341 & 0.273 & 396 & 0.327 & 628 & 0.998 \\
\hline 28 & 884 & 1.000 & 354 & 1.000 & 318 & 1.000 & 192 & 1.000 \\
\hline 29 & 2143 & 0.339 & 857 & 0.339 & 852 & 0.359 & 1418 & 1.000 \\
\hline 30 & 1350 & 0.612 & 540 & 0.612 & 533 & 0.647 & 534 & 0.999 \\
\hline 31 & 753 & 1.000 & 301 & 1.000 & 271 & 1.000 & 0 & 1.000 \\
\hline 32 & 1655 & 0.075 & 662 & 0.075 & 709 & 0.084 & 0 & 0.043 \\
\hline 33 & 1138 & 0.657 & 455 & 0.657 & 452 & 0.697 & 0 & 0.656 \\
\hline 34 & 593 & 0.331 & 237 & 0.330 & 295 & 0.423 & 405 & 1.000 \\
\hline 35 & 290 & 0.198 & 116 & 0.197 & 202 & 0.415 & 233 & 1.000 \\
\hline 36 & 1791 & 1.000 & 716 & 1.000 & 645 & 1.000 & 0 & 1.000 \\
\hline 37 & 4372 & 0.577 & 1749 & 0.577 & 1626 & 0.588 & 2573 & 1.000 \\
\hline industry & 59270 & 0.301 & 23708 & 0.301 & 23708 & 0.317 & 23708 & 0.501 \\
\hline
\end{tabular}

Notes: * The computed results of Plan 3 are based on $\beta=0.36$. 
banks' and the whole bank system's efficiency from an industry-wide point of view. From the industry-wide perspective, if all banks reduce their NPLs by the same ratio, the above argument is no longer true. More specifically, in this case, the relative efficiency of individual banks and the whole system is almost the same as their original level. Second, even though the reduction of NPLs is generally helpful in improving industry-wide efficiency, an incorrect reduction plan could make the improvement very insignificant, for example, again, reducing all banks' NPLs by the same ratio.

\section{Discussion and implications}

Over the last three decades, many economies, including Taiwan, have adopted financial reforms aimed at eliminating different restrictions on the financial sector. However, the financial liberalization may lead to banking crises. One of these crises is the increase in NPLs. To control NPLs and other financial risks, banking systems are still regarded as a regulated industry. For the regulator, the benefit of this study is to help evaluate possible NPL reduction plans. We introduce DEA efficiency estimates, the measure of net production per NPL ratio, to help evaluate NPL reduction plans. Using the measure, the regulator can identify the most efficient plan. Among the possible schemes, we compare four plans. Based on the above scenario analysis, we recommend Plan 4. The plan can improve industry-wide efficiency most. Moreover, different from Plans 1 and 3, the plan just focuses on a finite number of banks, helping identify the key units to improve. This may lower the expenses of reduction. In addition, focusing on limited units can also enable us to implement the reduction plan more easily.

The implications behind the empirical results are that the regulator should devise more incentive measures to control NPLs. Generally, however, regulatory authorities, including Taiwan's Financial Supervisory Commission, use punitive sanctions to control NPLs. For example, according to Taiwan's banking act, if a bank's NPL ratio exceeds $5 \%$, the authority will adopt punitive measures such as issuing an NPL improvement order, restriction on distributions of remuneration to directors and supervisors, restriction on distributions of surplus etc. Punitive sanctions are passive. For those whose NPL ratio does not exceed 5\%, the measures lack incentives to motivate them to improve. The implementation of Plan 4, however, requires incentive measures because the target bank's original E-NPL may not be very inefficient.

Besides efficiency, another important issue is what the consequences of the plans with the stability of the financial system are. The suggested approach cannot address this issue in its present form. However, after appropriate revision, we believe that the models can deal with the problem. The key point is to identify the position where the NPLs are riskier, that is, to identify each bank's ability to absorb NPL losses. Then, by dividing banks into several groups according to their ability and revising Model (11) to restrict different reduction targets for each group, we believe that the resulting reduction plan can achieve both stability and efficiency. 


\section{Summary and conclusions}

Increased NPLs have been a significant problem in many countries all over the world. The present paper has suggested a DEA-based approach for disaggregating an industrywide NPL reduction target into the aim of each bank so as to maximize banking system efficiency. For comparison, three other plans are also represented. Using a data set from Taiwan's banking industry, the empirical findings have showed that the proposed models can suggest a most efficient reduction plan; the plan focuses on improvement of a finite number of banks, which can be implemented more easily and could possibly lower the expenses of reduction. Possible applications of the findings are that the regulator or policy maker should provide more incentives to control NPLs because the target banks may not be relatively inefficient. Forcing banks to cut their NPLs by the same ratio is not encouraged; it is not at all helpful to improve the relative efficiency of the banks and the industry. Therefore, the present article has successfully provided policy makers an effective quantization approach to develop an efficient NPL reduction scheme, helping address the NPL control problem.

Future studies could extend the proposed approaches in a more practical way. For example, it may be more important to monitor a big bank than a small bank, because a big bank failure is more likely to produce a disastrous effect on the economy. Then, the question is how to incorporate the bank size variance into the model. It will be interesting to see additional research to accommodate this variance. Or, for another example, a bankers' association or regulatory agency may have funding for controlling NPLs. In such a case, future studies can explore how to fairly allocate the funding when designing a reduction plan. Finally, this paper only addresses the NPL reduction issue. There are many other risk factors affecting bank efficiency, e.g. the capital adequacy ratio. Another potential area for future research is to extend this study by covering more risk factors.

\section{Acknowledgements}

The author would like to thank three anonymous reviewers and Managing Editor of this journal for their constructive comments and suggestions. Financial support from the Ministry of Science and Technology of Taiwan (grant number MOST 105-2410-H166-001) is gratefully acknowledged.

\section{References}

Assaf, A. G.; Matousek, R.; Tsionas, E. G. 2013. Turkish bank efficiency: Bayesian estimation with undesirable outputs, Journal of Banking \& Finance 37: 506-517.

https://doi.org/10.1016/j.jbankfin.2012.09.009

Berger, A. N.; DeYoung, R. 1997. Problem loans and cost efficiency in commercial banks, Journal of Banking \& Finance 21: 849-870. https://doi.org/10.1016/S0378-4266(97)00003-4

Chiu, Y.-H.; Lin, J.-C.; Su, W.-N.; Liu, J.-K. 2015. An efficiency evaluation of the EU's allocation of carbon emission allowances, Energy Sources, Part B: Economics, Planning, and Policy 10: 192-200. https://doi.org/10.1080/15567249.2010.527900 
Erdinç, D.; Gurov, A. 2016. The effect of regulatory and risk management advancement on non-performing loans in European banking, 2000-2011, International Advances in Economic Research 22: 249-262. https://doi.org/10.1007/s11294-016-9591-y

Feng, C.; Chu, F.; Ding, J.; Bi, G.; Liang, L. 2015. Carbon Emissions Abatement (CEA) allocation and compensation schemes based on DEA, Omega 53: 78-89.

https://doi.org/10.1016/j.omega.2014.12.005

Fethi, M. D.; Pasiouras, F. 2010. Assessing bank efficiency and performance with operational research and artificial intelligence techniques: a survey, European Journal of Operational Research 204: 189-198. https://doi.org/10.1016/j.ejor.2009.08.003

Frija, A.; Chebil, A.; Speelman, S.; Buysse, J.; Van Huylenbroeck, G. 2009. Water use and technical efficiencies in horticultural greenhouses in Tunisia, Agricultural Water Management 96: 1509-1516. https://doi.org/10.1016/j.agwat.2009.05.006

Fujii, H.; Managi, S.; Matousek, R. 2014. Indian bank efficiency and productivity changes with undesirable outputs: a disaggregated approach, Journal of Banking \& Finance 38: 41-50.

https://doi.org/10.1016/j.jbankfin.2013.09.022

Ghosh, A. 2015. Banking-industry specific and regional economic determinants of non-performing loans: evidence from US states, Journal of Financial Stability 20: 93-104.

https://doi.org/10.1016/j.jfs.2015.08.004

Gomes, E. G.; Lins, M. P. E. 2008. Modelling undesirable outputs with zero sum gains data envelopment analysis models, Journal of the Operational Research Society 59: 616-623.

https://doi.org/10.1057/palgrave.jors.2602384

Holod, D.; Lewis, H. F. 2011. Resolving the deposit dilemma: a new DEA bank efficiency model, Journal of Banking \& Finance 35: 2801-2810. https://doi.org/10.1016/j.jbankfin.2011.03.007

Liu, W. B.; Meng, W.; Li, X. X.; Zhang, D. Q. 2010. DEA models with undesirable inputs and outputs, Annals of Operation Research 173: 177-194. https://doi.org/10.1007/s10479-009-0587-3

Louzis, D. P.; Vouldis, A. T.; Metaxas, V. L. 2012. Macroeconomic and bank-specific determinants of non-performing loans in Greece: a comparative study of mortgage, business and consumer loan portfolios, Journal of Banking \& Finance 36: 1012-1027.

https://doi.org/10.1016/j.jbankfin.2011.10.012

Luo, X. 2003. Evaluating the profitability and marketability efficiency of large banks: an application of data envelopment analysis, Journal of Business Research 56: 627-635.

https://doi.org/10.1016/S0148-2963(01)00293-4

Maggi, B.; Guida, M. 2011. Modelling non-performing loans probability in the commercial banking system: efficiency and effectiveness related to credit risk in Italy, Empirical Economics 41: 269-291. https://doi.org/10.1007/s00181-010-0379-2

Mester, L. J. 1996. A study of bank efficiency taking into account risk-preferences, Journal of Banking \& Finance 20: 1025-1045. https://doi.org/10.1016/0378-4266(95)00047-X

Pang, R.-Z.; Deng, Z.-Q.; Chiu, Y.-H. 2015. Pareto improvement through a reallocation of carbon emission quotas, Renewable and Sustainable Energy Reviews 50: 419-430.

https://doi.org/10.1016/j.rser.2015.05.022

Paradi, J. C.; Zhu, H. 2013. A survey on bank branch efficiency and performance research with data envelopment analysis, Omega 41: 61-79. https://doi.org/10.1016/j.omega.2011.08.010

Pasiouras, F. 2008. Estimating the technical and scale efficiency of Greek commercial banks: the impact of credit risk, off-balance sheet activities, and international operations, Research in International Business and Finance 22: 301-318. https://doi.org/10.1016/j.ribaf.2007.09.002

Pastor, J. M.; Serrano, L. 2005. Efficiency, endogenous and exogenous credit risk in the banking systems of the Euro area, Applied Financial Economics 15: 631-649.

https://doi.org/10.1080/09603100500065214 
Ray, S. C.; Hu, X. 1997. On the technically efficient organization of an industry: a study of U.S. airlines, Journal of Productivity Analysis 8: 5-18.https://doi.org/10.1023/A:1007751413007

Saha, P.; Bose, I.; Mahanti, A. 2016. A knowledge based scheme for risk assessment in loan processing by banks, Decision Support Systems 84: 78-88. https://doi.org/10.1016/j.dss.2016.02.002 Scardovi, C. 2016. Holistic active management of non-performing loans. Cham: Springer. https://doi.org/10.1007/978-3-319-25363-3

Stijepović, R. 2014. Recovery and reduction of non-performing loans-Podgorica approach, Journal of Central Banking Theory and Practice 3: 101-118. https://doi.org/10.2478/jcbtp-2014-0017

Sun, J.; Wu, J.; Liang, L.; Zhong, R. Y.; Huang, G. Q. 2014. Allocation of emission permits using DEA: centralised and individual points of view, International Journal of Production Research 52: 419-435. https://doi.org/10.1080/00207543.2013.829592

Vithessonthi, C. 2016. Deflation, bank credit growth, and non-performing loans: evidence from Japan, International Review of Financial Analysis 45: 295-305.

https://doi.org/10.1016/j.irfa.2016.04.003

Wu, H.; Du, S.; Liang, L.; Zhou, Y. 2013. A DEA-based approach for fair reduction and reallocation of emission permits, Mathematical and Computer Modelling 58: 1095-1101.

https://doi.org/10.1016/j.mcm.2012.03.008

Wu, J.; Chu, J.-F.; Liang, L. 2016b. Target setting and allocation of carbon emissions abatement based on DEA and closest target: an application to 20 APEC economies, Natural Hazards 84 (Supplement 1): 279-296. https://doi.org/10.1007/s11069-015-1973-6

Wu, J.; Zhu, Q.; Liang, L. 2016a. $\mathrm{CO}_{2}$ emissions and energy intensity reduction allocation over provincial industrial sectors in China, Applied Energy 166: 282-291.

https://doi.org/10.1016/j.apenergy.2016.01.008

Yang, C.-C. 2014. Evaluating the performance of banking under risk regulations: a slacks-based Data Envelopment Analysis assessment framework, Expert Systems 31(2): 176-184.

https://doi.org/10.1111/exsy.12020

Zhang, T. 2008. Environmental performance in China's agricultural sector: a case study in corn production, Applied Economics Letters 15: 641-645. https://doi.org/10.1080/13504850600721874 Zhu, N.; Wang, B.; Wu, Y. 2015. Productivity, efficiency, and non-performing loans in the Chinese banking industry, The Social Science Journal 52: 468-480.

https://doi.org/10.1016/j.soscij.2014.10.003

Chih-Ching YANG is an associate professor of the Department of Marketing Management in Central Taiwan University of Science and Technology, Taichung, Taiwan. His research interests focus on efficiency and productivity analysis. 